\title{
LIBERAÇÃO DE POTÁSSIO DE FRAÇÕES DE SOLOS E SUA CINÉTICA(1)
}

\author{
E. J . ME URE $\mathbf{R}^{(2)} \&$ R. M. V. CASTILHOS(3)
}

\begin{abstract}
RESUMO
Áci dos orgânicos de baixo peso molecular têm sido utilizados em estudos de cinética de liberação de potássio em solos. Este trabalho foi desenvolvido com o objetivo de investigar a cinética de liberação de potássio nas frações granulométricas de dois solos do Rio Grande do Sul. Foram utilizadas amostras superficiais $(0-20 \mathrm{~cm})$ do horizonte A de um Gleissolo Háplico e de um Chernossolo E bânico, nas quais foi quantificado o potássio li berado dos solos após 15 extrações sucessivas com ácido oxálico $0,01 \mathrm{~mol} \mathrm{~L}^{-1}$ de 1 a $864 \mathrm{~h}$, totalizando um período de $3.409 \mathrm{~h}$. As quantidades de potássio liberadas das frações de ambos os solos decresceram na seqüência argila $>$ silte $>$ areia. A descrição da cinética de li beração do potássio pela equação parabólica de difusão mostrou que o processo ocorreu a diferentes velocidades, em duas fases, para as frações areia e silte, e em três fases, para a fração argila. As quantidades de potássio extraídas das amostras dos solos representaram 3,4\% do K-total no Gleissolo e 6,2\% do K-total no Chernossolo.
\end{abstract}

Termos de indexação: potássio disponível, equação parabólica de difusão, ácido oxálico.

(1) Parte da Tese de Doutorado do segundo autor, apresentada à Faculdade de Agronomia, Universidade Federal do Rio Grande do Sul - UFRGS. Recebido para publicação em agosto de 2000 e aprovado em julho de 2001.

(2) Professor do Departamento de Solos da Universidade Federal do Rio Grande do Sul - UFRGS. Caixa Postal 776, CEP 90001-970 Porto Alegre (RS). Bolsista do CNPq. E-mail: egon.meurer@ufrgs.br

(3) Professora do Departamento de Solos da Universidade Federal de Pelotas - UFPEL. Caixa Postal 354, CEP 96001-970 Pelotas (RS). E-mail: rmvcastilhos@ufpel.tche.br 


\title{
SUMMARY: RELEASE OF POTASSIUM FROM SOIL FRACTIONS AND ITS KINETICS
}

\begin{abstract}
Low molecular organic acids havebeen utilized in kinetic studies on potassi um rel ease from K-bearing minerals in soils. This study was undertaken to investigate the kinetics of potassium releasefrom two soil s of thestate of Rio Grandedo Sul, Brazil. A horizon samples $(0-20 \mathrm{~cm})$ of a Gleisol and a Chernosol were extracted with oxalic acid $0.01 \mathrm{~mol} \mathrm{~L}^{-1}$, in fifteen sequential extractions ranging from 1 to $864 \mathrm{~h}$, through a period of 3,409 h. Oxal ic acid induced $\mathrm{K}$ releasefrom sand, silt and day in both soils. Theparabolic diffusion equation showed that potassium release occurred at different rates, in two phases for sand and silt, and in three phases for day, at different rates. The amounts of potassium released from soil fractions were only $3.4 \%$ and $6.2 \%$ of total $\mathrm{K}$, in the Gleisol and in the Chernosol, respectively.
\end{abstract}

Index terms: available potassium, parabolic diffusion equation, oxalic acid.

\section{INTRODUÇÃO}

Estudos para quantificar as taxas de liberação de potássio para as plantas, de minerais fontes deste elemento em solos, possibilitam mel hor entendimento da sua disponibilidade e fornecem subsídios para ajustar as recomendações de adubação potássica. Nesses trabal hos, vários métodos têm sido utilizados, dentre os quais soluções sal inas diluídas como $\mathrm{BaCl}_{2}$, $\mathrm{SrCl}_{2}, \mathrm{CaCl}_{2}$ (Munn et al., 1976; Simard et al., 1992), tetrafenilborato de sódio (Reed \& Scott, 1962; Cox et al., 1996) e resinas trocadoras de cátions, saturadas com prótons ou cálcio (Martin \& Sparks, 1983; Martin \& Sparks, 1985; Dhillon \& Dhillon, 1990; Meurer \& Rosso, 1997). Ácidos orgânicos de baixo peso molecular, como cítrico e oxálico, também têm sido utilizados em estudos de cinética de liberação de potássio em sol os (Mehta et al., 1995). Song \& Huang (1988) utilizaram tais ácidos, cítrico e oxálico, em estudos de liberação de potássio em amostras de biotita, muscovita, microcline e ortoclásio. Os ácidos orgânicos podem facilitar a intemperização de minerais por meio da formação de complexos orgânico-metálicos (Schnitzer \& Kodama, 1976; Tam, 1986).

O potencial para liberação do potássio é proporcional à quantidade de minerais primários e secundários, fontes de potássio, presentes no solo, e à capacidade das plantas em reduzir a concentração de K na solução a concentrações que provoquem a sua liberação dos minerais, o que ocorre principalmentena rizosfera (Mitsios \& Rowell, 1987; Rao \& Khera, 1994). Além disso, a velocidade com que o potássio é liberado depende, também, do tipo de mineral, dotamanho das partículas, de seu grau, de intemperização e de sua difusão no solo.

Alguns trabal hos têm quantificado a liberação de potássio das frações granulométricas dos solos. De modo geral, os minerais primários, como os feldspatos e as micas, tendem a concentrar-se nas frações mais grosseiras (areia e silte), enquanto os minerais secundários na fração argila. Simard et al. (1992) estudaram a dinâmica de liberação de potássio das frações silte fino, médio e grosso e da fração argila de quatro sol os do Canadá, num período de $3.200 \mathrm{~h}$, por meio de 15 extrações seqüenciais com ácido cítrico $0,5 \mathrm{mmol} \mathrm{L}^{-1}$. As maiores quantidades e taxas de liberação de potássio foram obtidas na fração siltefino, que continha vários minerais fontes de potássio (fel dspatos, micas e vermiculitas).

Este trabal ho foi desenvol vido com o objetivo de avaliar as quantidades de potássio extraídas seqüencialmente pela ação do ácido oxálico em amostras de um Gleissolo e de um Chernossolo do estado do Rio Grande do Sul, descrevendo a cinética de liberação pela equação parabólica de difusão.

\section{MATERIAL E MÉTODOS}

O estudo foi realizado em laboratórios do Departamento de Solos da Faculdade deAgronomia da Universidade Federal do Rio Grande do Sul, no período de fevereiro a julho de 1999. Foram utilizadas amostras secas ao ar e peneiradas a $2 \mathrm{~mm}$ (TFSA) do horizonte A $(0-20 \mathrm{~cm})$ de dois solos, um Gleissolo Háplico e um Chernossolo Ebânico, onde foram identificados minerais fontes de potássio (Castilhos, 1999).

Algumas características destes sol os encontramse no quadro 1. A distribuição do tamanho de partículas foi determinada pelo método do hidrômetro, conforme descrito em Day (1965). O pH em água, a matéria orgânica ea capacidade de troca de cátions (CTC) foram determinados conforme descrito em Tedesco et al. (1995). O fracionamento das amostras dos solos foi feito por dispersões sucessivas com $\mathrm{NaOH} 0,1 \mathrm{~mol} \mathrm{~L}^{-1}$. A fração areia $(0,05-2 \mathrm{~mm})$ foi separada por peneira e as frações 
silte $(2-50 \mu \mathrm{m})$ e argila $(<2 \mu \mathrm{m})$ por sedimentação natural da suspensão em meio líquido, com pH ajustado para 10 pela adição de $\mathrm{NaOH}$, conforme Tanner \& J ackson (1947). Na fração argila, foi feita a remoção da matéria orgânica, usando-se peróxido de hidrogênio como agente oxidante, em banhomaria.

Em cada fração, foram determinados o potássio total (K-total) e o potássio não-trocável (K-não trocável), extraídos, respectivamente, com ácido fluorídrico concentrado e com ácido nítrico $\left(\mathrm{HNO}_{3}\right)$ $1 \mathrm{~mol} \mathrm{~L}^{-1}$ fervente (Pratt, 1973). Considerando as perdas do potássio trocável que ocorrem durante o processo de fracionamento, tomou-se o potássio extraído com o $\mathrm{HNO}_{3}$ como sendo o potássio nãotrocável.

Liberação do potássio - para estudar a liberação do potássio, foi utilizado o procedimento já adotado em diversos trabalhos, entre os quais os de Feigenbaum et al., 1981; Martin \& Sparks, 1983; Havlin et al., 1985; Simard et al., 1992. O procedimento está fundamentado nas observações de que a concentração do potássio na solução de equilíbrio deve ser mantida baixa, na ordem de $1,0 \mathrm{mmol} \mathrm{L}^{-1}$, para provocar a liberação do potássio dos minerais fontes do el emento (Rausell-Colom et al., 1965; Mitisios \& Rowell, 1987). Estas condições são alcançadas com a renovação da solução de equilíbrio, em extrações seqüenciais, comoa utilizada neste trabal ho e em outros estudos desta natureza.

Desta forma, em tubos de centrífuga de $30 \mathrm{~mL}$ foram adicionados, em duplicatas, separadamente, 2,00 g de areia, silte e argila, de cada solo, e, sobre estes, $20 \mathrm{~mL}$ de ácido oxálico $0,01 \mathrm{~mol} \mathrm{~L}^{-1}$ (relação 1:10). Na primeira extração, o tempo de contato e agitação foi de uma hora, em agitador mecânico horizontal, com 110-120 oscilações por minuto. As soluções foram então centrifugadas e o potássio foi determinado, no sobrenadante, por fotometria de chama. Às amostras remanescentes nos tubos de centrífuga foram adicionadas novas alíquotas de $20 \mathrm{~mL}$ do mesmo ácido, repetindo-se esse procedimento até um total de 15 extrações. A cada reposição da solução extratora, os tubos foram agitados por duas horas em agitador mecânico horizontal, na mesma velocidade descrita anteriormente e, depois, manualmente, uma vez ao dia. O tempo decontato de cada extração foi variável, desde 1 até $864 \mathrm{~h}$, totalizando um tempo acumulado de 3.409 h $(1,16,29,113,168,164,168,164,163$, $197,210,312,312,528$ e 864 h).

Descrição da liberação de potássio - a relação entrea quantidade acumulada de potássio, extraída seqüencialmente pela ação do ácido oxálico, das frações areia, siltee argila com otempo de equilíbrio das amostras com o ácido oxálico, em cada extração, foi descrita pela equação parabólica de difusão ( $K t K \alpha^{-1}=a+b t^{1 / 2}$ ), em que $K t$ representa $a$ quantidade de potássio liberado no tempo te $\mathrm{K} \alpha \mathrm{a}$ quantidade total de potássio liberado das amostras (Feigenbaum et al., 1981; Martin \& Sparks, 1983; Havlin et al., 1985; Simard et al., 1992).

\section{RESULTADOS E DISCUSSÃO}

Os teores de K-total, de K-não-trocável e o potássio liberado das frações granulométricas, dos dois solos, durante os tempos de equilíbrio com o ácido oxálico, estão apresentados no quadro 2 . As quantidades de K-total nas três frações granulométricas do Gleissolo mostraram-se acentuadamente superiores às do Chernossolo, embora as quantidades totais de potássio liberadas

\section{Quadro 1. Características do horizonte A $(0-20 \mathrm{~cm})$ dos solos}

\begin{tabular}{|c|c|c|}
\hline Característica & Gleissolo Háplico & Chernossolo E bânico \\
\hline Material de origem & Sedimentos aluviais & Sedimentos basalto \\
\hline Areia, $\mathrm{g} \mathrm{kg}^{-1}$ & 260 & 320 \\
\hline Silte, $\mathrm{g} \mathrm{kg}^{-1}$ & 360 & 310 \\
\hline Argila, $\mathrm{g} \mathrm{kg}^{-1}$ & 380 & 370 \\
\hline $\mathrm{pH}$ água & 4,9 & 5,4 \\
\hline Matéria orgânica, g kg-1 & 26 & 37 \\
\hline CTC, $\mathrm{mmol}_{\mathrm{c}} \mathrm{kg}^{-1}$ & 88 & 227 \\
\hline $\mathrm{K}$ total ${ }^{(1)}, \mathrm{mg} \mathrm{kg}^{-1}$ & 5.336 & 2.189 \\
\hline $\mathrm{K} \mathrm{HNO}_{3}{ }^{(2)}, \mathrm{mg} \mathrm{kg}^{-1}$ & 121 & 147 \\
\hline K não trocável(3), $\mathrm{mg} \mathrm{kg}^{-1}$ & 68 & 88 \\
\hline K trocável(4), mg kg-1 & 53 & 59 \\
\hline
\end{tabular}

\footnotetext{
(1) Castilhos (1999) - Extração com ácido fluorídrico concentrado e dissolução em HCl 6 mol L-1 (Pratt, 1973). ${ }^{\text {(2) Extração com ácido }}$

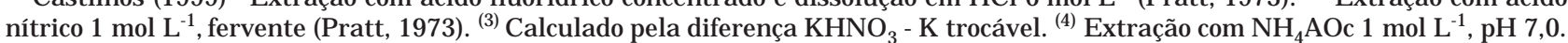


pela ação do áci do oxálico atéas 3.409 h nãotenham apresentado diferenças tão acentuadas. A areia, nos dois solos, foi a fração que liberou as menores quantidades de potássio, $100 \mathrm{mg} \mathrm{kg}^{-1}$ de $\mathrm{K}$, no Chernossolo, e $132 \mathrm{mg} \mathrm{kg}^{-1}$ de K, no Gleissolo. Embora as quantidades não sejam muito diferentes (Figura 1), o teor de K-total na fração areia do Gleissolo foi maior, em cerca de 10 vezes, ao do Chernossolo. Nos dois solos, a fração areia foi constituída predominantemente pelo mineral quartzo, apresentando, como fonte potencial de potássi o, al guns fel dspatos e micas (Castilhos, 1999). A diferença nas quantidades de potássio liberadas pode estar associada à composição química dos feldspatos e ao tipo de mica presente na fração do Gleissolo, que pode ser predominantemente do tipo trioctaedral, quelibera o potássio mais lentamente, que a do tipo octaedral (Song \& Huang, 1988).

A liberação de potássio da fração silte de ambos os solos apresentou, inicialmente, comportamento similar ao da fração areia nas cinco primeiras extrações (Figura 1), ocorrendo, a partir desta, um aumento progressivo das quantidades de potássio liberadas, al cançando $185 \mathrm{mg} \mathrm{kg}^{-1}$ deK, no Gleissolo, e $147 \mathrm{mg} \mathrm{kg}^{-1}$ de $\mathrm{K}$, no Chernossolo. A maior quantidade do potássioliberado pela fração silte em relação à fração areia, em ambos os solos, justificase pela presença de maiores quantidades de K-total nesta fração e pela presença de mai ores quantidades de feldspatos e micas (Castilhos, 1999), além do menor tamanho da partícula do silte em relação à da areia.

A fração argila, em ambos os solos, liberou maior quantidade de potássio, apresentando comportamento distinto, caracterizado por uma liberação mais rápida na fase inicial. Em relação às quantidades totais dessorvidas, as quantidades liberadas nesta fase (até 46 h) corresponderam a 48\%, no Gleissolo, e a $58 \%$ no Chernossolo (Figura 1). Possivelmente, o potássioliberado nesta primeira fasefoi proveniente desítios deadsorção menos específicos, situados nas entrecamadas de argilominerais 2:1, próximos das bordas das partículas ou das superfícies dos fel dspatos que estariam mais acessíveis ao extrator.

Quadro 2. Teores de K-total, de K-não-trocável e quantidade de K-total liberado pela ação do ácido oxálico das frações areia, silte e argila, das amostras do horizonte $A(0-20 \mathrm{~cm})$ dos solos

\begin{tabular}{|c|c|c|c|c|c|c|c|c|c|}
\hline \multirow{2}{*}{ Solo } & \multicolumn{3}{|c|}{ K-total(1) } & \multicolumn{3}{|c|}{ K-não-trocável(2) } & \multicolumn{3}{|c|}{ K liberado(3) } \\
\hline & Areia & Silte & Argila & Areia & Silte & Argila & Areia & Silte & Argila \\
\hline & \multicolumn{9}{|c|}{$-\mathrm{mg} \mathrm{kg}^{-1}$} \\
\hline Gleissolo Haplico & 2.843 & 5.197 & 7.117 & 73 & 37 & 302 & 132 & 185 & 211 \\
\hline Chernossolo E bânico & 279 & 3.385 & 2.841 & 42 & 51 & 333 & 100 & 147 & 157 \\
\hline
\end{tabular}

(1) Extração com ácido fluorídrico concentrado e dissol ução com HCl 6 mol L-1 (Pratt, 1973). (2) Extração com $\mathrm{HNO}_{3} 1$ mol L ${ }^{-1}$, fervente (Pratt, 1973). ${ }^{(3)}$ Quantidade acumulada em 15 extrações sucessivas com ácido oxálico 0,01 mol L-1 de uma até $864 \mathrm{~h}$ de contato, totalizando um período de $3.409 \mathrm{~h}$.
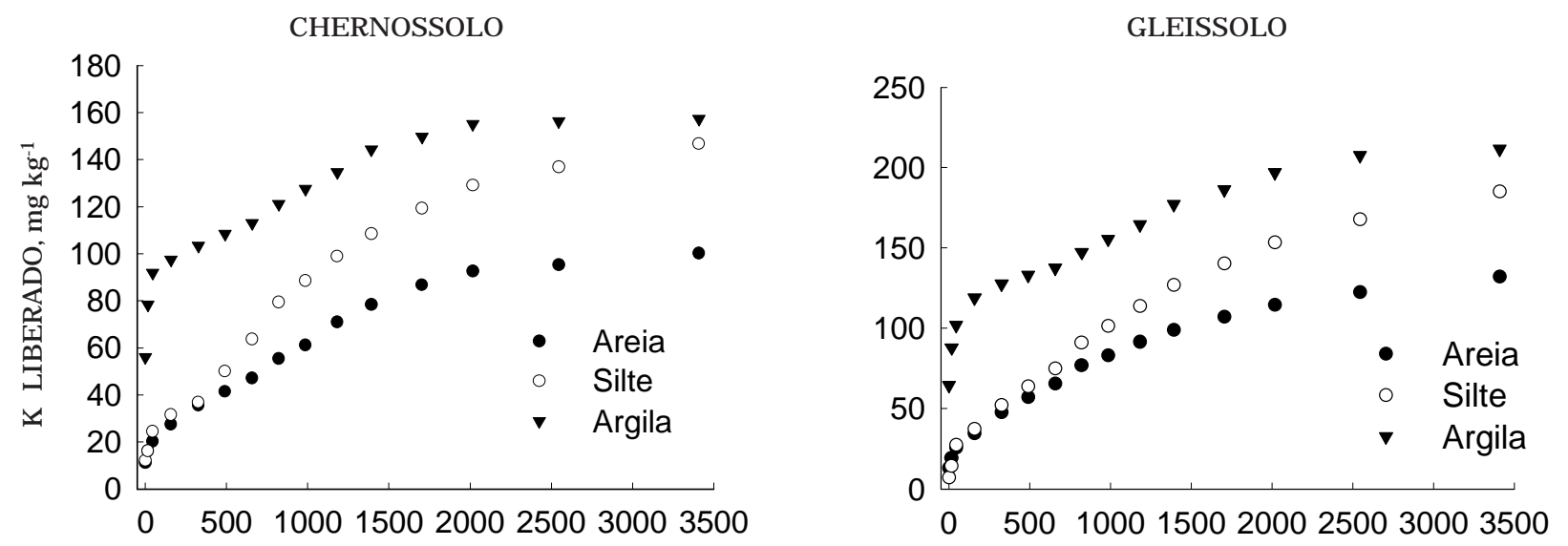

TEMPO, $h$

Figura 1. Liberação cumulativa de potássio das frações granulométricas do Chernossolo e do Gleissolo, considerando o tempo. 
Nas fases subseqüentes, em que a liberação foi mais lenta, esta pôde ter sido controlada pela taxa de difusão do potássio do centro das partículas em direção às bordas externas dos minerais, parcialmente intemperizados. Para os feldspatos, após a liberação rápida do potássio dos sítios mais externos, a liberação adicional deste nutriente, dos sítios internos, só ocorrerá se houver quebra na estabilidade das ligaç̃os Al-O e Si-O, por meio das reações de protonação e complexação pelo ácido oxálico, o que aconteceria mais lentamente, em virtude da proteção exercida pela fina camada de $\mathrm{Si}-\mathrm{Al}-\mathrm{O}$, que, normal mente, é formada em torno do mineral, durante sua intemperização, dificultando o acesso do extrator (Rich, 1968).

Comportamento semel hantefoi obtido por Datta \& Sastry (1993), para as frações argila fina e argila grossa de três sol os aluviais da Í ndia, submetidas a 10 extrações com $\mathrm{HNO}_{3} 1 \mathrm{~mol} \mathrm{~L}^{-1}$ fervente, tendo as primeiras extrações contribuído com 44 a $71 \%$ do $\mathrm{K}$ total liberado, com uma taxa de liber ação constante, de $3,5 \times 10^{-2}$ a $4,0 \times 10^{-2} \mathrm{~min}^{-1}$, que, após três extrações, caiu rapidamente para valores de $2 \times 10^{-3}$ a $5 \times 10^{-3} \mathrm{~min}^{-1}$.

Song \& Huang (1988), estudando a cinética de liberação do potássio de minerais puros (biotita, muscovita, mi croclina e ortoclásio) pela ação do ácido oxálico 0,01 mol L-1 observaram, também, que a liberaçãofoi mais rápida inicialmente. Esses autores atribuíram este fato à exposição de íons potássio na superfície das partículas dos minerais e à possibilidade, durante o processo de preparação das amostras, de ocorrer algum tipo dedano na estrutura dos minerais, próximo à superfície das partículas. Esses danos poderiam facilitar o acesso ao potássio situado nas entrecamadas da mica ou no interstício dos feldspatos, tornado-os mais susceptíveis à ação do extrator.
A descrição da cinética de liberação do potássio pela equação parabólica dedifusão (Figura 2) indicou que, para as frações areia e silte, a liberação do potássio ocorreu em duas fases distintas e, para a fração argila, em três fases, com diferentes taxas de vel ocidade (Quadro 3, declividade). Os valores das taxas, de maneira geral, foram semelhantes, com exceção dos obtidos na primeira fase da fraçãoargila, em que a taxa de liberação de potássio no Chernossolo foi 1,85 vez superior $\left(3,96 \times 10^{-2} \mathrm{~h}^{-1}\right)$ à do Gleissolo $\left(2,14 \times 10^{-2} \mathrm{~h}^{-1}\right)$. As diferentes fases e taxas de liberação do potássio das frações granulométricas desses sol os podem ser explicadas pelos diferentes teores de $\mathrm{K}$-total e pel os minerais fontes de potássio encontrados na fração. Nas frações areia e silte, os minerais fontes de potássio identificados foram micas e significativas quantidades de feldspatos; na fração argila, foram identificados feldspatos, micas e esmectitas (Castilhos, 1999).

A contribuição estimada de potássio de cada fração, considerando o percentual em que ocorreu no sol o e a quantidade total liberada até as $3.409 \mathrm{~h}$, é mostrada no quadro 4. A quantidade total de potássio liberado, de $181,30 \mathrm{mg} \mathrm{kg}^{-1}$ de $\mathrm{K}$, no Gleissolo, e de 135,75 $\mathrm{mg} \mathrm{kg}^{1}$ de K, no Chernossolo, correspondeu, respectivamente, a somente 3,4 e $6,2 \%$ dos teores de K-total encontrados nesses solos (Quadro 1). A fração que mais contribuiu foi a argila, em ambos os sol os, com 43 e 44\%, seguida da silte; a contribuição da fração areia ficou entre 19 e 24\%.

As quantidades de potássio liberadas nas amostras dos dois solos pela ação do ácido oxálico $0,01 \mathrm{~mol} \mathrm{~L}^{-1}$ (Quadro 4) foram superiores às extraídas pelo ácido nítrico $1 \mathrm{~mol} \mathrm{~L}^{-1}$ fervente (Quadro 1), o que revela ter o ácido oxálico, além do K-não trocável, provocado a liberação de potássio da estrutura dos minerais nesses solos.
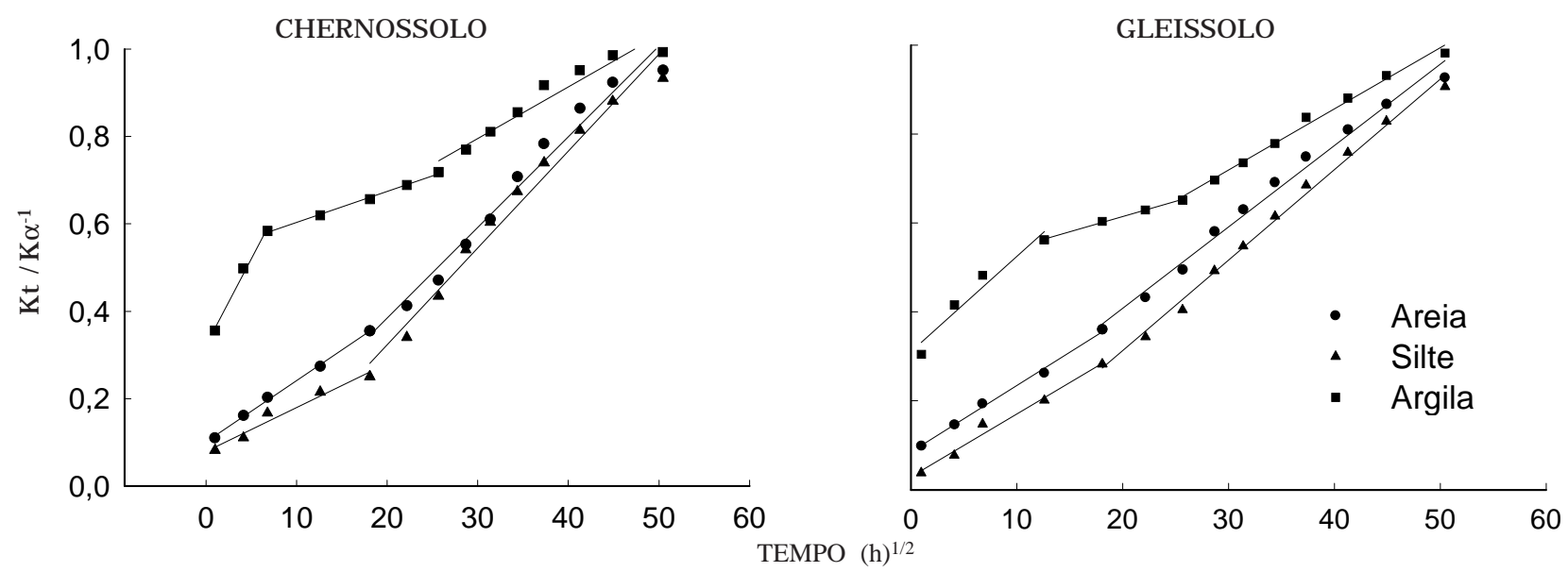

Figura 2. Cinética da liberação de potássio das frações granulométricas do Chernossolo e do Gleissolo descrita pela equação parabólica de difusão. 
Quadro 3. Coeficientes da equação parabólica de difusão $\left(K t K \alpha^{-1}=a+b t^{1 / 2}\right)$ para as diferentes fases de li beração de potássio nas frações granulométricas do Gleissolo Háplico e do Chernossolo E bânico

\begin{tabular}{|c|c|c|c|c|c|c|c|}
\hline \multirow[b]{2}{*}{ Fração } & & \multicolumn{3}{|c|}{ Gleissolo } & \multicolumn{3}{|c|}{ Chernossolo } \\
\hline & & Interseção & Declividade & $\mathbf{r}$ & Interseção & Declividade & $\mathbf{r}$ \\
\hline \multirow[t]{2}{*}{ Areia } & 1a fase & $\begin{aligned} & 8,43 \times 10^{-2} \\
P< & 0,0009\end{aligned}$ & $\begin{aligned} & 1,50 \times 10^{-2} \\
P<0,0001 & \end{aligned}$ & $0,997^{* *}$ & $P<0,0002$ & $\begin{aligned} & 1,40 \times 10^{-1} \\
& 0,0001\end{aligned}$ & $0,999 * *$ \\
\hline & $2^{\text {a fase }}$ & $\begin{aligned} & 4,24 \times 10^{-2} \\
P & <, 1190\end{aligned}$ & $P<0,0001$ & $0,994 * *$ & $P<0,0474$ & $\begin{array}{l}2,07 \times 10^{-2} \\
<0,0001\end{array}$ & $0,988^{* *}$ \\
\hline \multirow[t]{2}{*}{ Silte } & $1^{\text {a fase }}$ & $\begin{array}{l}2,88 \times 10^{-2} \\
P<0,0886\end{array}$ & $P<0,0010$ & $0,999 *$ & $\begin{array}{r}7,91 \times 10^{-2} \\
<0,0072\end{array}$ & $P<0,0031$ & $0,981^{* *}$ \\
\hline & $2^{a}$ fase & $\begin{array}{l}-9,48 \times 10^{-2} \\
P<0,0010\end{array}$ & $P<0,0001$ & $0,997^{* *}$ & $P<0,0173$ & $\begin{array}{l}2,22 \times 10^{-2} \\
P<0,0001\end{array}$ & $0,989 * *$ \\
\hline \multirow[t]{3}{*}{ Argila } & $1^{\text {a fase }}$ & $\begin{array}{l}3,10 \times 10^{-1} \\
P<0,008\end{array}$ & $P<0,0293$ & $0,970^{* *}$ & 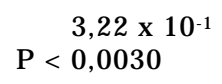 & $P<0,0060$ & $0,995^{* *}$ \\
\hline & $2^{a}$ fase & $\begin{aligned} & 4,78 \times 10^{-1} \\
& P<0,0001\end{aligned}$ & $\begin{array}{l}\quad 6,80 \times 10^{-3} \\
<0,0016\end{array}$ & $0,998^{* *}$ & $\begin{aligned} & 5,33 \times 10^{-1} \\
& <0,0001\end{aligned}$ & 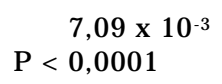 & $0,998 * *$ \\
\hline & $3^{a}$ fase & $P<0,0001$ & 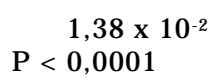 & $0,995^{* *}$ & $P<0,0005$ & $P<0,0022$ & $0,967 * *$ \\
\hline
\end{tabular}

Quadro 4. Contribuição estimada das frações areia, silte e argila para o K-total liberado dos solos pela ação do áci do oxálico 0,01 mol L ${ }^{-1}$, em 15 extrações seqüenciais, de 1 até 864 h de contato, totalizando um período de $3.409 \mathrm{~h}$

\begin{tabular}{lcccc}
\hline \multirow{2}{*}{ Solo } & \multirow{2}{*}{ K-total liberado } & \multicolumn{3}{c}{ Frações } \\
\cline { 3 - 4 } & & Argila & Silte & Areia \\
\cline { 3 - 4 } & & & $\mathrm{mg} \mathrm{kg}^{-1}$ de solo & \\
Gleissolo Haplico & $181,30(100)$ & $80,35(44)$ & $66,61(37)$ & $34,34(19)$ \\
Chernossolo Ebânico & $135,75(100)$ & $58,23(43)$ & $45,45(33)$ & $32,07(24)$ \\
\hline
\end{tabular}

Entre parênteses expressa-se a percentagem em relação ao total liberado.

Resultados semelhantes foram encontrados por Mehta et al. (1995) para quatro solos da Índia, que também obtiveram maior extração de potássio com ácido oxálico em relação ao cítrico e nítrico, nas mesmas concentrações. As diferenças foram atribuídas às quantidade de íons $\mathrm{H}^{+} \mathrm{e}$ de ligantes dos ácidos orgânicos e às diferenças na capacidade de complexação dos ligantes. Os íons $\mathrm{H}^{+}$podem deslocar o íons $\mathrm{K}^{+}$e desestabilizar a estrutura dos minerais pela incorporação aos oxigênios apicais da lâmina tetraedral, reduzindo a carga da camada (Datta \& Sastry, 1993).

Para os ácidos orgânicos, além da ação dos íons $\mathrm{H}^{+}$, deve ser considerado o efeito adicional dos ligantes orgânicos, cujos grupos $\mathrm{OH}$ eCOOH tendem a formar complexos com os cátions da solução e da estrutura dos minerais, acelerando a sua decomposição (Song \& Huang 1988).

\section{CONCLUSÕES}

1. O ácido oxálico provocou a liberação de potássio das frações areia, silte e argila de ambos os solos, que decresceram na seqüência argila >silte >areia.

2. A descrição da cinética de liberação do potássio pela equação parabólica de difusão mostrou que o processo ocorreu, a diferentes vel ocidades, em duas fases, para as frações areia e silte, e em três fases, para a fração argila. 
3. As quantidades de potássio liberadas das amostras dos sol os representaram somente 3,4\% do K-total no Gleissolo Háplico e 6,2\% do K-total no Chernossolo Ebânico.

\section{LITE RATURA CITADA}

CASTILHOS, R.M.V. Suprimento de potássio em solos cultivados com arroz irrigado e sua relação com a mineralogia, forma e cinética de liberação. Porto Alegre, Universidade Federal do Rio Grande do Sul, 1999.175p. (Tese de Doutorado)

COX, A.E.; J OERN, B.C. \& ROTH, C.B. Nonexchangeable ammonium and potassium determination in soils with a modified sodium tetraphenylboron method. Soil Sci. Soc. Am. J., 60:114-120, 1996.

DATTA, S.C. \& SASTRY, T.G. Potassium release in relation to mineralogy of silt and days. J. Ind. Soc. Soil Sci., 41:452458, 1993.

DAY, P. Particle fractionation and particle-size analysis. In: BLACK, C.A., ed. Methods of soil analysis. Madison, America Society of Agronomy, 1965. p.545-567 (Agronomy Series, 9)

DHILLON, S.K. \& DHILLON, K.S. Kinetics of release of nonexchangeable potassium by cation saturated resins from red (Alfisols), black (Vertisols) and alluvial (Inceptisols) of India. Geoderma, 47:283-300, 1990.

FEIGENBAUM, S.; EDELSTEIN, R. \& SHAINBERG, I. Release rate of potassium and structural cations from micas to ion exchangers in dilute solutions. Soil Sci. Soc. Am. J ., 45:501$506,1981$.

HAVLIN, J .L.; WSETFALL, D.G. \& OLSEN, S.R. Mathematical models for potassium release kinetics in calcareous solis. Soil Sci. Soc. Am. J., 49:371-376, 1985.

MARTIN, H.W. \& SPARKS, D.L. Kinetics of nonexchangeable potassium release from two coastal plain soils. Soil Sci. Soc. Am. J ., 47:883-887, 1983.

MARTIN, H.W. \& SPARKS, D.L. On the behavior of nonexchangeable potassium. Comm. Soil Sci. Plan. Anal., 16:133-162, 1985.

MEHTA, S.C.; MEEL, K.S. \& GREWAL, E.A. Release of nonexchangeable potassium in Entisols. J. Ind. Soc. Soil Sci., 43:351-356, 1995.

MEURER, E.J . \& ROSSO, J .I . Cinética de liberação de potássio em solos do Rio Grande do Sul. R. Bras. Ci. Solo, 21:553558, 1997.
MITSIOS, I.K. \& ROWELL, D.L. Plant uptake of exchangeable and nonexchangeable potassium. I. Measurement and modelling for onions roots in Chalky Boulder day soil. J . Soil Sci., 38:55-63, 1987.

MUNN, D.A.; WILDING, L.P. \& MCLEAN, E.O. Potassium release from sand, silt and clay soil separates. Soil Sci. Soc. Am. J., 40:364-366, 1976.

PRATT, P.F. Potassium. In: BLACK, C.A. Methods of soil analysis. Part 1. Madison, American Society of Agronomy, 1973. p.1022-1032. (Agronomy Series, 9)

RAO, S.C. \& KHERA, M.S. Potassium replenischment capacity of soil at their minimal exchangeable $\mathrm{K}$ in relations to clay mineralogy. Z. Pflanz., 157:467-470, 1994.

RAUSELL-COLOM, J .A.; SWEETMAN, T.R. \& NORRISH. Studies on the artificial weathering of micas. In: HALLSWORTH, E.G. \& CRAWFORD, D.V., eds. Experimental pedology. London, Butterworths, 1965. p.4070.

REED, M.G. \& SCOTT, A.D. Kinetics of potassium release from biotiteand muscovitein sodium tetraphenyl boron solutions. Soil Sci. Am. Proc., 25:437-440. 1962.

RICH, C.I. Mineralogy of soil potassium. In: KILMER, V.J .; YOUNTS, S.E. \& BRADY, N.C., eds. The role of potassium in agriculture. Madison, American Society of Agronomy, 1968. p.79-108.

SCHNITZER, M. \& KODAMA, H. The dissolution of micas by fulvic acid. Geoderma, 15:381-391, 1976.

SIMARD, R.R.; KIMPE, C.R. \& ZIZKA, J. Release of potassium and magnesium from soil fractions and it kinetics. Soil Sci. Soc. Am. J ., 56:1421-1428, 1992.

SONG, S.K. \& HUANG, P.M. Dynamics of potassium release from potassium-bearing minerals as influenced by oxalic and citric acids. Soil Sci. Soc. Am. J ., 52:383-390, 1988.

TAM, K.H. Degradation of soil minerals by organic acids. In: HUANG, P.M. \& SCHNITZER, M., eds. Interactions of soil minerals with natural organics and microbes. Madison, Soil. Science Society of American, 1986. 606p.

TANNER, C.B. \& J ACKSON, M.L. Nomographs of sedimentation times for soil particles under gravity or centrifugal acceleration. Soil Sci. Soc. Am. Proc., 12:60-65, 1947.

TEDESCO, M.J .; GIANELLO, C.; BISSANI, C.A.; BOHNEN, H. $\&$ VOLKWEISS, S. Análise de solos, plantas e outros materiais. 2.ed. Porto Alegre, Universidade Federal do Rio Grande do Sul, 1995. 174p. (Boletim Técnico, 5) 
